\title{
Eleven-Years Inversion of the Green Corona Emission
}

by

Ester Antonucci

November 1973

Meproduction in wole or in part

is permitted for any purpose of

the United States Government.

SUIPR Report No. 549

Office of Naval Research

Contract N00014-67-A-0ll2-0068

National Aeronautics and Space Administration

Grant NGR 05-020-559

and

National Science Foundation

Grant GA-3II38

\section{INSTITUTE FOR PLASMA RESEARCH STANFORD UNIVERSITY, STANFORD, CALIFORNIA}


ELEVEN-YEARS INVERSION OF THE GREEN CORONA EMISSION

by

Ester Antonucci*

Office of Naval Research

Contract N00014-67-A-0112-0068

National Aeronautics and Space Administration

Grant NGR 05-020-559

and

National Science Foundation

Grant GA-31138

Reproduction in whole or in part is

permitted for any purpose of the

United states Government

SUIPR Report No. 549

November 1973

Institute for plasma Research

Stanford University

stanford, California

Submitted to Solar Physics.

*ESRO/NASA Fellow, on leave from Torino University, Italy. 


\title{
Eleven-years Inversion of the Green Corona Emission \\ Ester Antonucci \\ Institute for Plasma Research, Stanford University \\ Stanford, California 94305 \\ On leave from Torino University - Italy
}

\begin{abstract}
A cross-correlation analysis of coronal green line intensity (5303 $)$ and interplanetary magnetic field polarity for the period 1947-1970 shows that the coronal features are organized in a constant pattern with respect to the 4-sector structure through the solar cycle. A sudden inversion of the coronal pattern with respect to the sector structure takes place at the solar minima. The high emission regions of the green corona are located near the solar magnetic sector boundaries having polarities $(-,+),(+,-),(-,+)$ during cycles $18,19,20$ respectively in the northern hemisphere, and $(+,-),(-,+),(+,-)$ in the southern hemisphere.
\end{abstract}




\section{DATA ANALYS IS}

The degree of correlation between the green corona emission and the polarity pattern of the interplanetary magnetic field is studied for the years 1947-1970. Polarity data of the interplanetary magnetic field, inferred from high latitude geomagnetic observations (Svalgaard, 1972) and synoptic tables of the intensity of the green corona emission line (5303\&) are used in this analysis. These tables, prepared by Sykora (1973, personal communication), are expressed in the Pic du Midi photometric scale. The green line intensity, for the central meridian, has been calculated as an average of the intensities measured at the limbs, 7 days before and 7 days later respectively. The intensity data are given for six latitude belts $\left(57^{\circ} .5 \mathrm{~N}-\right.$ $37^{\circ} .5 \mathrm{~N} ; 37^{\circ} .5 \mathrm{~N}-17^{\circ} .5 \mathrm{~N} ; 17^{\circ} .5 \mathrm{~N}-2^{\circ} .5 \mathrm{~S} ; 2^{\circ} .5 \mathrm{~N}-17^{\circ} .5 \mathrm{~S} ; 17^{\circ} .5 \mathrm{~S}-37^{\circ} .5 \mathrm{~S} ; 37^{\circ} .5 \mathrm{~S}-$ $57^{\circ} .5 S$ ) in form of 3-day averages. One-day interpolated values of the corona intensity are computed from the tables.

The polarity data of the interplanetary magnetic field are expressed as a time series of +1 or -1 daily values respectively for positive sectors (interplanetary magnetic fleld away from the sun) and for negative sectors. These data are then smoothed by applying a 7-day running mean to the data. In fact in the analysis only large-scale polarity features of the interplanetary magnetic field, i.e. its sector structure, are of interest. The coronal intensity data set also contains essentially information on long1 ived, broad coronal features; in fact the daily values are interpolated from the 3-day averages of the synoptic tables.

Very long-term variations such as the 11-year variation of the green line emission or the 1-year variation of the polarity data (Rosenberg and Coleman, 1969) are removed from both data sets by subtracting a 27-day running mean from the data. 


\section{Coronal Emission and IMF Sector Structure Correlation}

A recurrence tendency persistent over periods of a few months, related to the rotation of the sun, is characteristic of both coronal and polarity data. This is an indication of the stability in time of the coronal patterns and the sector structure (Svalgaard, 1972; Antonucci and Svalgaard, 1973). The purpose of this study is to investigate the possibility of significant relationships in phase between coronal emission zones and interplanetary magnetic sectors, therefore between coronal features and weak photospheric magnetic regions of one polarity or the other (Wilcox et al., 1969). For each latitude zone the coronal emission intensity is crosscorrelated with the polarity data of the interplanetary magnetic field with a time lag varying from -30 days to +30 days, over successive 2-year intervals. The polarity time series is previnusly corrected by 4.5 days in order to take into account the transit time of the solar wind from the sun surface to the earth (Wilcox et al., 1969). A statistically significant correlation between the two data sets exists when the cross-correlation coefficients have values $z 0.1$, namely the hypothesis of zero correlation is rejected at the $1 \%$ level of significance.

In Table I and I the lags in days of the maximum value of the first negative or positive peak of the cross-correlation functions and the relative cross-correlation coefficients c are tabulated respectively for northern and southern heliolatitudes. If the cross-correlation coefficient of the peak is $<0.1$ it is not reported. The peaks show a regular shape that permits a determination of the time delays between coronal and polarity features with an accuracy of about 0.1 day. The years tabulated on the first column of Table I and II are the centers of the 2-year intervals. 
The analysis of the time delays indicates that for each latitude zone they are fairly constant through a solar cycle. As Table III shows, the maximum standard deviation of the time delay, averaged over a solar cycle, is 1.7 days (the values of the zone $2^{\circ} .5 \mathrm{~N}-17^{\circ} .5 \mathrm{~s}$ during cycle 18 and of the zone $37^{\circ} .5 \mathrm{~s}-57^{\circ} .5 \mathrm{~s}$ during cycle 19 are excluded). Furthermore the average time delays of cycle 18, 19 and 20 do not differ more than 3 days for each latitude, except the zone $2^{\circ} .5 \mathrm{~N}-17^{\circ} .5 \mathrm{~s}$. The values in parenthesis in Table I and II are not included in the evaluations of the average delays and cross-correlation coefficients reported in Table III.

A second characteristic common to each latitude is that the time delays refer to positive cross-correlation coefficients during cycle 18 and cycle 20 and to negative ones during cycle 19. The values that do not follow this scheme are in parenthesis in Table I and II. These deviations show a tendency to occur during periods of maximum solar activity and at high latitudes. In Table III the average cross-correlation coefficients for each latitude and each cycle are reported. They do not show any relevant dependence on heliolatitude.

\section{Interpretation of the Results}

The quasi-regular pattern of the cross-correlation functions between green corona emission and sector structure of the interplanetary magnetic field leads to a rather simple interpretation. When the cross-correlation coefficients are positive the average lags (Table III) represent the time delay between correlated features of the corona and the sector structure. Therefore we can choose a maximum of the coronal emission intensity as reference. This reference maximum will precede or follow (depending on the posi- 
tive or negative sign of the time delay) a maximum in the polarity data which corresponds to the center of a positive sector. In fact the polarity data are simulated by a time series of positive and negative values (for positive and negative sectors respectively), which, because of the smoothing, has maxima or minima corresponding to sector centers. In case of negative crosscorrelation coefficients, the time delay can be interpreted as the lag between the reference maximum and the center of a negative sector.

In Figure 1, the relative lag between the reference maximum of the coronal emission ( $I_{\max }$ ) and the center of negative or positive sectors (indicated by - and + respectively) is schematized for each latitude zone and solar cycle. The different latitude zones are indicated by Roman numerals, corresponding to those of Table III. Around the positions of the sector centers, $\sim 7$ days intervals are represented. They indicate the average interplanetary magnetic sectors (Wilcox, 1968). Dashed Iines represent negative sectors and continuous lines positive sectors. The scheme of Figure 1 indicates that the reference emission maximum relative to the northern latitude zones is close to a $(-,+)$ sector boundary during cycle 18 and 20 and a $(+,-)$ boundary during cycle 19 . The reference maximum relative to the southern miódle and high latitude zones is close to a $(+,-)$ sector boundary during cycle 18 and 20 and $a(-,+)$ sector boundary during cycle 19 . The lags relative to the zone $2.5 \mathrm{~N}-17^{\circ} .5 \mathrm{~S}$ show a pattern similar to the lags relative to the northern hemisphere but with a wider spread of values. In conclusion the high emission zones of the corona do show an organization inside the sector structure of the interplanetary (and in consequence photospheric) magnetic fields, which is constant through a solar 
cycle. The emission maxima are closely related to sector boundaries. At the solar minima the coronal features shift suddenly by about 7 days ( $90^{\circ}$ of longitude) with respect to the 4 -sector structure. The emission maxima are still related to sector boundaries but of opposite polarities with respect to the preceding solar cycle. Therefore an inversion between high and low emission zones of the corona takes place with respect to the sector structure at the sunspot minima. It is clear that this analysis implies just a relative shift of the two patterns.

The cyclic inversion of the coronal emission is present in both hemispheres, but during the same solar cycle the northern and southern coronal emission regions are close to boundaries of opposite polarities. This implies a displacement of $90^{\circ}$ in heliolongitude of the northern coronal emitting regions with respect to the southern enitting regions at middle and high latitude.

\section{Acknowledgements}

I thank Dr. J. Sykora for providing the green line intensity data and Dr. J. M. Wilcox and Dr. L. Svalgaard for discussions. The author is an ESRO/NASA fellow. This work was supported in part by the office of Naval Research under contract N00014-67-A-0112-0068, by the National Aeronautics and Space Administration under Grant NGR 05-020-559, and by the Atmospheric Sciences Section of the National Science Foundation under Grant GA-31138. 


\section{References}

Antonucci, E. and Svalgaard, L.: 1973, Solar Physics (to be published)

Rosenberg, R. L. and Coleman, P. J., Jr.: 1969, J. Geophys. Res., 74, 5611. Svalgaard, L.: 1972, Dan. Meteorol. Inst., Geophys. Pap. 29.

Wilcox, J. M.: 1968, Space Sci. Rev., 8, 258.

Wilcox, J. M., Severny, A. and Colburn, D.S.: 1969, Nature 224, 353. 
TABLE 1

Corona Emission and Sector structure Cross-Correlation Time Delays and Coefficients

North Hemisphere

\begin{tabular}{|c|c|c|c|c|c|c|}
\hline & \multicolumn{2}{|c|}{$17^{\circ} .5 \mathrm{~N}-2^{\circ} .5 \mathrm{~S}$} & \multicolumn{2}{|c|}{$37^{\circ} .5 \mathrm{~N}-17^{\circ} .5 \mathrm{~N}$} & \multicolumn{2}{|c|}{$57^{\circ} .5 \mathrm{~N}-37^{\circ} .5 \mathrm{~N}$} \\
\hline & $1 \mathrm{ag}$ & $\mathrm{c}$ & lag & $c$ & lag & $c$ \\
\hline 1949 & 3.9 & +.27 & 5.3 & +.24 & 6.3 & +.22 \\
\hline 1951 & 2.7 & +.18 & 4.2 & +.20 & 6.0 & +.21 \\
\hline 1953 & 2.1 & +.21 & 5.3 & +.37 & 4.8 & +.34 \\
\hline .1955 & 2.3 & -.32 & 0.8 & -.23 & 3.0 & -.20 \\
\hline 1957 & 2.9 & -.31 & -1 & -.18 & 2.3 & -.16 \\
\hline 1959 & 3.1 & -.12 & 3.7 & -.17 & $(-1.1)$ & $(+.27)$ \\
\hline 1961 & 6.7 & -.17 & - & - & $(-2.0)$ & $(+.012)$ \\
\hline 1963 & 3.7 & -.31 & 3.7 & -.32 & 3.4 & -.14 \\
\hline 1965 & 3.6 & +.20 & 5.1 & +.22 & - & - \\
\hline 1967 & $(11.3)$ & $(+.22)$ & 4.3 & +.20 & 3.5 & +.18 \\
\hline 1969 & 4.8 & +.26 & 2.7 & +.23 & $(-0.5)$ & $(-.14)$ \\
\hline
\end{tabular}




\section{TABLE II}

Corona Emission and Sector structure Cross-Correlation Time Delays and Coefficients

South Hemisphere

\begin{tabular}{|c|c|c|c|c|c|c|}
\hline \multirow[b]{3}{*}{1949} & \multicolumn{2}{|c|}{$2.5 \mathrm{~N}-17^{\mathrm{o}} .5 \mathrm{~s}$} & \multicolumn{2}{|c|}{$17^{\circ} .5 \mathrm{~s}-37^{\circ} .5 \mathrm{~s}$} & \multicolumn{2}{|c|}{$37^{\circ} .5 \mathrm{~s}-57^{\circ} .5 \mathrm{~s}$} \\
\hline & $\mathrm{lag}$ & $\mathrm{c}$ & $\operatorname{lag}$ & $\mathrm{c}$ & lag & c \\
\hline & 4.5 & +.23 & $(-5.5)$ & $(-.17)$ & $(-3.1)$ & $(-.21)$ \\
\hline 1951 & -1.9 & +.20 & -2.3 & +.34 & -1.6 & +.39 \\
\hline 1953 & -2.5 & +.19 & -2.8 & +.25 & -1.5 & +.24 \\
\hline 1955 & 5.3 & -.26 & - & - & -7.5 & -.13 \\
\hline 1957 & $(0.5)$ & $(+.24)$ & -3.7 & -.10 & $(-8.9)$ & $(+.22)$ \\
\hline 1959 & - & - & -3.1 & -.15 & -2.8 & -.24 \\
\hline 1961 & 5.3 & -.15 & -6.1 & -.10 & 3.0 & -.19 \\
\hline 1963 & 5.3 & -.27 & -4.7 & -.13 & -1.5 & -.10 \\
\hline 1965 & - & - & - & - & - & - \\
\hline 1967 & $(-4.5)$ & $(-.14)$ & - & - & -3.0 & +.10 \\
\hline 1969 & 6.9 & +.26 & -3.8 & +.36 & -2.7 & +.33 \\
\hline
\end{tabular}


TABLE III

Corona Emission and Sector Structure Cross-Correlation

Average Time Delays and Coefficients

\begin{tabular}{|c|c|c|c|c|c|}
\hline & & Cycle & 18 & 19 & 20 \\
\hline I & $57^{\circ} .5 \mathrm{~N}-37^{\circ} .5 \mathrm{~N}$ & $\begin{array}{l}\text { lag } \\
\mathrm{c}\end{array}$ & $\begin{array}{r}5.7 \pm 0.6 \\
+0.26\end{array}$ & $\begin{array}{c}2.9 \pm 0.5 \\
-0.17\end{array}$ & $\begin{array}{r}3.5 \pm 0.0 \\
+\quad 0.18 \\
\end{array}$ \\
\hline I I & $37^{\circ} .5 \mathrm{~N}-17^{\circ} 5 \mathrm{~N}$ & $\begin{array}{l}\text { lag } \\
\mathrm{c}\end{array}$ & $\begin{array}{r}4.9 \pm 0.5 \\
+0.27\end{array}$ & $\begin{array}{c}1.8 \pm 1.7 \\
-0.22\end{array}$ & $\begin{array}{c}4.0 \pm 1.0 \\
+0.22 \\
\end{array}$ \\
\hline I II & $17^{\circ} .5 \mathrm{~N}-2.5 \mathrm{~S}$ & $\begin{array}{l}\operatorname{lag} \\
\mathrm{c}\end{array}$ & $\begin{array}{r}2.9 \pm 0.7 \\
+.0 .22\end{array}$ & $\begin{array}{c}3.7 \pm 1.5 \\
-0.24\end{array}$ & $\begin{array}{r}4.2 \pm 0.6 \\
+0.23 \\
\end{array}$ \\
\hline IV & $2.5 \mathrm{~N}-17^{\circ} .5 \mathrm{~s}$ & $\begin{array}{c}\operatorname{lag} \\
\mathrm{c}\end{array}$ & $\begin{array}{r}0.1 \pm 3.1 \\
+0.21 \\
\end{array}$ & $\begin{array}{c}5.3 \pm 0.0 \\
-0.23 \\
\end{array}$ & $\begin{array}{r}6.9 \pm 0.0 \\
+\quad 0.26 \\
\end{array}$ \\
\hline V & $17^{\circ} \cdot 5 \mathrm{~S}-37^{\circ} .5 \mathrm{~S}$ & $\begin{array}{c}\text { lag } \\
\mathrm{c}\end{array}$ & $\begin{array}{r}-2.5 \pm 0.3 \\
+0.29\end{array}$ & $\begin{array}{c}-4.4 \pm 1.1 \\
-0.12 \\
\end{array}$ & $\begin{array}{r}-3.8 \pm 0.0 \\
+0.36 \\
\end{array}$ \\
\hline VI & $37^{\circ} .5 \mathrm{~s}-57^{\circ} .5 \mathrm{~s}$ & $\begin{array}{c}\operatorname{lag} \\
\mathrm{c}\end{array}$ & $\begin{array}{c}-1.5 \pm 0.1 \\
+0.31\end{array}$ & $\begin{array}{c}-2.2 \pm 3.7 \\
-0.16\end{array}$ & $\begin{array}{r}-2.8 \pm 0.2 \\
+0.21\end{array}$ \\
\hline
\end{tabular}




\section{Figure Caption}

Figure 1. The relative time lags between maxima of coronal emission intensity (5303\&) $I_{\max }$ and the center of positive $(+)$ or negative $(-)$ sectors are represented separately for northern and southern hemisphere and for cycle 18, 19 and 20 . The intervals around the sector centers represent the 7 days average magnetic sector (dashed lines for negative sectors, continuous lines for positive sectors). Each latitude zone is indicated with Roman numerals corresponding to those of Table III. 
GREEN CORONA EMISSION RELATIVE TO THE IMF SECTOR STRUCTURE

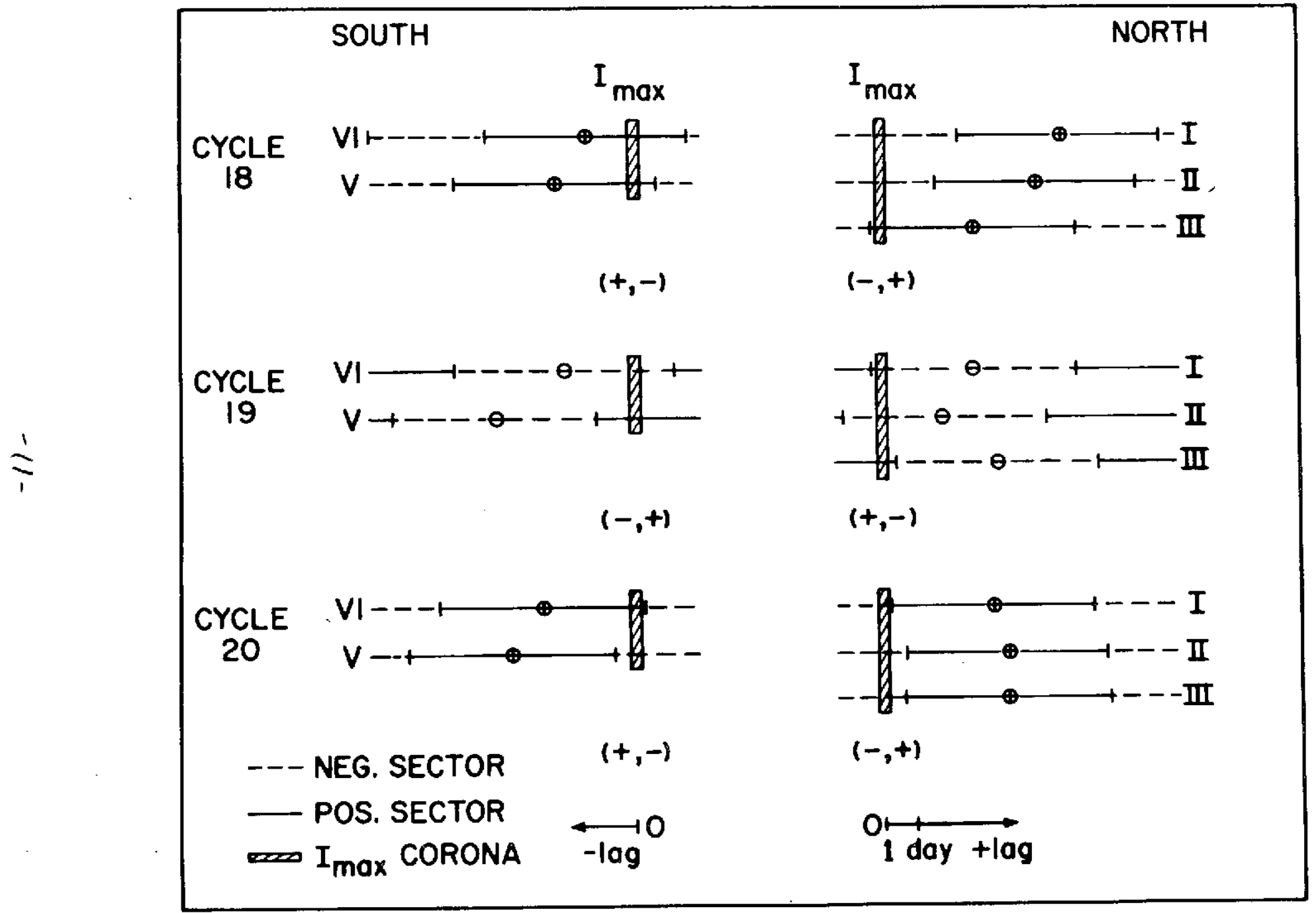


UNCLASSIFIED

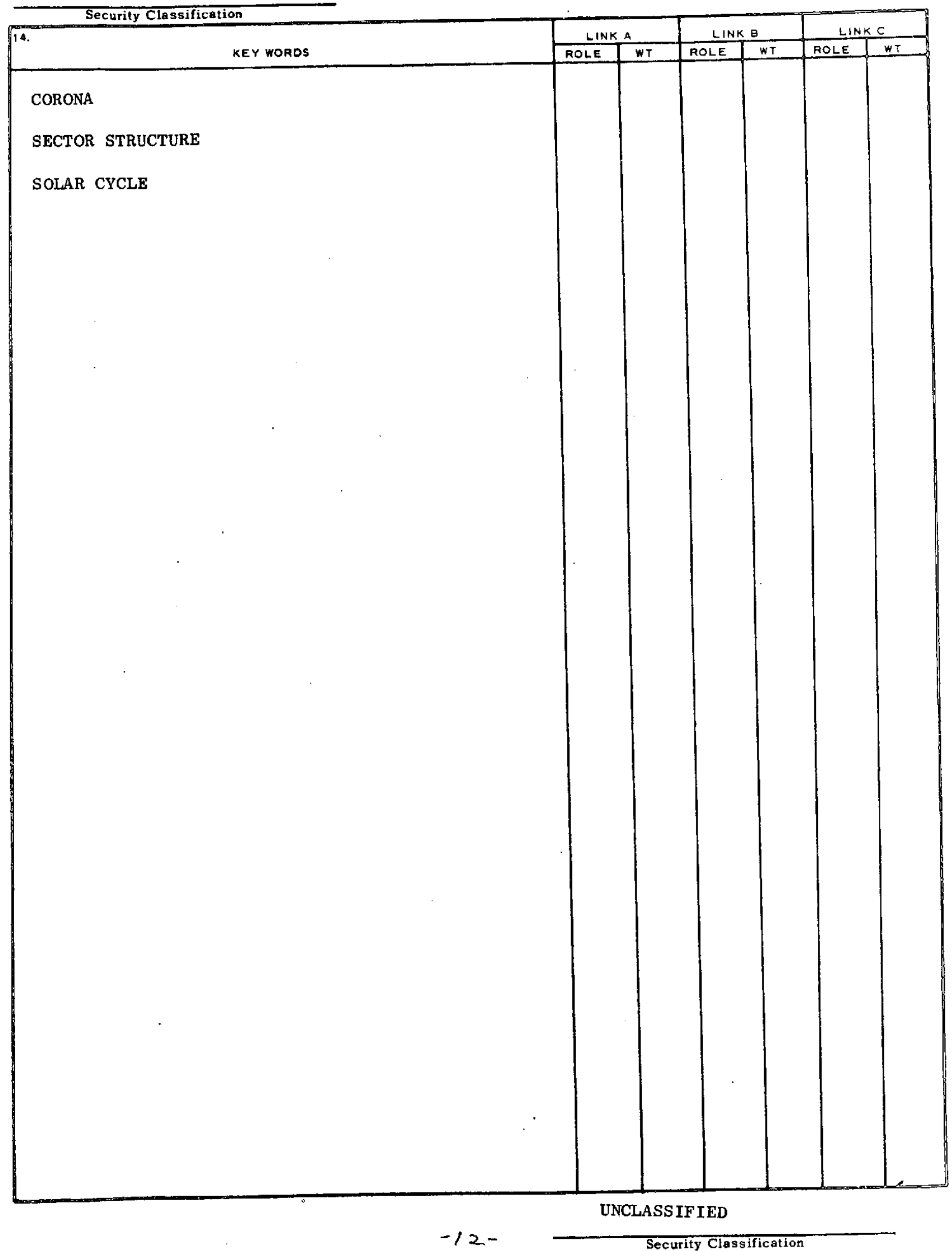


(Security classification of title, body af abstract and indexins ennolation must be entered when the overall teport is classified) 2a. REPORT SECUAITY CLASSIFICATION

Institute for Plasma Research

Stanford University

UNCLASS IF IED

Stanford, California 94305

3. REPORT TITLE

ELEVEN-YEARS INVERSION OF THE GREEN CORONA EMISSION

4. OESCRIPTIYE NOTES (Type of report and inclusive detes)

Scientific Technical

5. AUTHOR(S) (First name, middfo initial, last name)

Ester Antonucci

\begin{tabular}{|c|c|}
\hline 6. REPORT RATE, 1973 & 7a. TOTAL NO. OF PAGES \\
\hline $\begin{array}{l}\text { 8a. CONTRACT OR GRANT NO. } \\
\text { NOOO14-67-A-0112-0068 } \\
\text { b. PROJECT NO. }\end{array}$ & $\begin{array}{l}\text { 9a. ORIGINATOR"5 REPORT NUMBERIS) } \\
\text { SUIPR Report No. } 549\end{array}$ \\
\hline c. & $\begin{array}{l}\text { 9b. OTHER REPORT NO(S) (Any other numbers that may be assigned } \\
\text { this report) }\end{array}$ \\
\hline
\end{tabular}

10. DISTRIBUTION STATEMENT

This document has been approved for public release and sale; its distribution is unlimited.

11. SUPPLEMENTARY NOTES

TECH, OTHER

12. SPONSORING MILITARY ACTIVITY Office of Naval Research 800 North Quincy Street Arlington, Virginia 22217

13. ABSTRACT

A cross-correlation analysis of coronal green line intensity (5303\&) and interplanetary magnetic field polarity for the period 1947-1970 shows that the coronal features are organized in a constant pattern with respect to the 4-sector structure through the solar cycle. A sudden inversion of the coronal pattern with respect to the sector structure takes place at the solar minima. The high emission regions of the green corona are located near the solar magnetic sector boundaries having polarities $(-,+),(+,-),(-,+)$ during cycles $18,19,20$ respectively in the northern hemisphere, and $(+,-),(-,+),(+,-)$ in the southern hemisphere. 